\title{
Article \\ Early Schizophrenia and Bipolar Disorder Patients Display Reduced Neural Prepulse Inhibition
}

\author{
Rodrigo San-Martin ${ }^{1}$, Maria Inês Zimiani ${ }^{1,+}$, Milton Augusto Vendramini de Ávila ${ }^{2}$, Rosana Shuhama ${ }^{2,3}$, \\ Cristina Marta Del-Ben ${ }^{2,3}$, Paulo Rossi Menezes ${ }^{3,4}{ }^{\mathbb{D}}$, Francisco José Fraga ${ }^{5}$ and Cristiane Salum ${ }^{1, *}$ (D)
}

1 Centro de Matemática, Computação e Cognição, Universidade Federal do ABC, São Bernardo do Campo 09606-045, Brazil; rodrigo.san@ufabc.edu.br

2 Ribeirão Preto Medical School, Universidade de São Paulo, Ribeirão Preto 14040-900, Brazil; milton_avila@usp.br (M.A.V.d.Á.); roshuhama@gmail.com (R.S.); delben@fmrp.usp.br (C.M.D.-B.)

3 Population Mental Health Research Center, Universidade de São Paulo, São Paulo 01246-903, Brazil; pmenezes@usp.br

4 Department of Preventive Medicine, Faculdade de Medicina, Universidade de São Paulo, São Paulo 01246-903, Brazil

5 Centro de Engenharia, Modelagem e Ciências Sociais Aplicadas, Universidade Federal do ABC, Santo André 09210-580, Brazil; francisco.fraga@ufabc.edu.br

* Correspondence: cristiane.salum@ufabc.edu.br; Tel.: +55-(11)-23206273

+ In memorian.

check for

updates

Citation: San-Martin, R.; Zimiani,

M.I.; de Ávila, M.A.V.; Shuhama, R.; Del-Ben, C.M.; Menezes, P.R.; Fraga, F.J.; Salum, C. Early Schizophrenia and Bipolar Disorder Patients Display Reduced Neural Prepulse Inhibition. Brain Sci. 2022, 12, 93. https://doi.org/10.3390/ brainsci12010093

Academic Editor: Jung Seok Choi

Received: 16 November 2021

Accepted: 29 December 2021

Published: 11 January 2022

Publisher's Note: MDPI stays neutral with regard to jurisdictional claims in published maps and institutional affiliations.

Copyright: (C) 2022 by the authors. Licensee MDPI, Basel, Switzerland. This article is an open access article distributed under the terms and conditions of the Creative Commons Attribution (CC BY) license (https:// creativecommons.org/licenses/by/ $4.0 /)$.

\begin{abstract}
Background: Altered sensorimotor gating has been demonstrated by Prepulse Inhibition (PPI) tests in patients with psychosis. Recent advances in signal processing methods allow assessment of neural PPI through electroencephalogram (EEG) recording during acoustic startle response measures (classic muscular PPI). Simultaneous measurements of muscular (eye-blink) and neural gating phenomena during PPI test may help to better understand sensorial processing dysfunctions in psychosis. In this study, we aimed to assess simultaneously muscular and neural PPI in early bipolar disorder and schizophrenia patients. Method: Participants were recruited from a population-based case-control study of first episode psychosis. PPI was measured using electromyography (EMG) and EEG in pulse alone and prepulse + pulse with intervals of 30,60, and $120 \mathrm{~ms}$ in early bipolar disorder $(n=18)$ and schizophrenia $(n=11)$ patients. As control group, 15 socio-economically matched healthy subjects were recruited. All subjects were evaluated with Rating Scale, Hamilton Rating Scale for Depression, and Young Mania Rating Scale questionnaires at recruitment and just before PPI test. Wilcoxon ranked sum tests were used to compare PPI test results between groups. Results: In comparison to healthy participants, neural PPI was significantly reduced in PPI30 and PPI60 among bipolar and schizophrenia patients, while muscular PPI was reduced in PPI60 and PPI120 intervals only among patients with schizophrenia. Conclusion: The combination of muscular and neural PPI evaluations suggested distinct impairment patterns among schizophrenia and bipolar disorder patients. Simultaneous recording may contribute with novel information in sensory gating investigations.
\end{abstract}

Keywords: sensory gating; electroencephalography; psychosis; schizophrenia; bipolar disorder; EU-GEI; neural PPI

\section{Introduction}

Patients with bipolar disorder (BP) and patients with schizophrenia (SZ) show overlaps of symptoms and deficits [1-6] that challenge the dichotomy proposed in Kraepelin's original classification of manic-depressive psychosis and dementia praecox [7], or the affective and non-affective psychosis of more recent diagnostic classifications. Both are heritable [8], respond similarly to antipsychotics $[9,10]$, share common genetic causes $[11,12]$, illness 
course and cognition impairments [13-16], and there is interchange in diagnosis in a fraction of these patients [17]. Sensory processing impairments seem also to be shared among $\mathrm{BP}$ and SZ patients [18], but the extension of this superposition still needs to be clarified.

The most common way of evaluating sensory-motor gating impairments is the muscular prepulse inhibition (PPI) test. This test evaluates the eye-blink startle reflex reduction when a weak Prepulse (PP) stimulus precedes an intense Pulse (P) stimulus by few milliseconds [19-23]. This measure recruits the acoustic startle rapid response pathway, constituted by the cochlear root nucleus, caudal pontine reticular nucleus (PnC), and motoneurons [24]. In parallel, the inferior and superior colliculus and the pedunculopontine tegmental nucleus (PPN) are also activated by the stimuli. As the PnC on the rapid pathway may be inhibited by the PPN in the slower pathway, it has been hypothesized that this slower circuit activation by the PP inhibits the startle response evoked by P, resulting in the PPI phenomenon. Additionally, there are higher order structures, cortico-striato-pallido-pontine (CSPP), which overlap with several impaired structures in patients with psychosis [20,24-27]. The muscular (eye-blink) PPI effect reflects higher order neural impairments as an indirect measure, thus considered a "pontine portal" to these deficits [20].

Reduction in PPI evaluated by measure orbicularis muscle contraction during acoustic stimulation through the analysis of electromyography (EMG) has been consistently reported in SZ [22,28-32] and euthymic BP [33-36]. However, PPI evaluation in patients with psychoses is a challenging task, as numerous factors influence its outcome, ranging from ethnicity [37] to drug treatment [38-41]. Our recent meta-analysis revealed only a moderate effect size for muscular PPI in patients with schizophrenia, with high heterogeneity of results between studies, mainly related with methodological aspects of studies [32].

Patients with BP and SZ also display sensory gating deficits that are evaluated by electroencephalography, through the auditory elicited event-related potential (ERP) components P50, mismatch negativity (MMN), and P300 [42]. In those studies, patients with SZ show larger effect sizes than patients with BP in P50 [43-45], MMN [46,47], and P300 amplitude and latency [43,48-51], when compared to healthy controls. Neural PPI evaluates the neural gating phenomenon in the time window of 100-200 ms, whose latency is not explored by any other sensory gating paradigms [52]. However, neural PPI measurements have rarely been performed due to neural signal contamination resulting from strong muscular contractions elicited by the PPI-test stimuli. Fortunately, recent improvements on signal processing now support signal contamination reduction, allowing neural PPI assessment using electroencephalogram (EEG) alongside with classic eye-blink (muscular) [52]. The neural PPI is a more direct measure than the eye-blink muscular PPI and its psychopathological levels have been associated to eye-blink PPI impairment in SZ [53-56], but not in BP $[34,57]$. Thus, the concurrent muscular and neural PPI recording to assess the gating phenomena may be a promising approach to reveal dysfunctions and brain processing differences in $\mathrm{BP}$ and SZ patients with psychosis, considering that they occur at different timing and are underlied by different neural circuits [58,59].

In the present study, the primary aim was to assess simultaneously muscular and neural PPI in SZ and BP patients, in early stages of psychosis, and compare with age-sexeducation matched healthy subjects. A secondary aim was to evaluate the benefit of using the neural PPI test to investigate sensory gating in patients with psychosis. We hypothesized that neural PPI might be more sensitive to psychopathology levels changes than the traditional test. Finally, another aim of this study was to evaluate psychopathological levels related to psychosis, depression, and mania states concerning to the EMG- and EEG-PPI levels. 


\section{Materials and Methods}

\subsection{Participants}

Participants had already been enrolled in the "Schizophrenia and other psychosis Translational Research: Environment and Molecular Biology" (STREAM) project, part of the multinational EU-GEI Project [60-62]. In that project, participants were included if they lived in the defined catchment area and presented for the first time in their lives to mental health services due to psychotic episodes. Potential participants were excluded if there was evidence of psychotic symptoms precipitated by an organic cause, or transient psychotic symptoms resulting from acute intoxication, as defined by the ICD-10. Controls came from a population-based sample of individuals without history of contact with mental health services due to psychotic symptoms with sex- and age-distribution similar to the general population. A total of 55 subjects aged between 18 and 40 years were then recruited from that study and participated in the PPI recordings, including 13 patients with SZ, 21 patients with $\mathrm{BP}$, and 21 healthy controls (CT), matched with patients according to gender, age group, and educational level. All participants were evaluated at the Early Intervention in Psychosis Program of the Clinical Hospital of the Ribeirão Preto Medical School, University of São Paulo (HC-FMRP-USP). All tests were carried out by a healthcare professional (clinician, nurse, or psychologist) belonging to the clinic health service team.

Participants signed an Informed Consent Form containing information about the reasons, objectives, procedures, risks, and benefits of the study to which they were invited to participate, and were informed that their participation was voluntary, being able to withdraw at any time without loss to their attendance at the institution. Moreover, participants were guaranteed the right to receive information and to have any questions answered, even though this could affect their willingness to continue participating. They were told that anonymity was ensured, and all provided information would be kept confidential. The local research ethics committee approved the study (process No. 32293214.7.0000.5594/2017).

\subsection{Clinical Assessment}

Severity of psychotic symptoms was evaluated with the Brief Psychotic Rating Scale (BPRS) [63], the Hamilton Rating Scale for Depression (HAM-D) [64] test was used to assess severity of depression symptoms, and the Young Mania Rating Scale (YMRS) $[65,66]$ was used to assess manic symptoms severity. Additionally, at the PPI test session day, participants had their hand preference evaluated by the Edinburgh Handedness Inventory (EHI) [67]. Treatments with atypical and typical antipsychotics, mood stabilizers, and benzodiazepines were also recorded. All participants were assessed at STREAM recruitment day and at the PPI session day by clinicians.

\subsection{Prepulse Inhibition Test Session}

Just after clinical assessment, participants seated on a comfortable chair, were told to stare at a mark in the center of a wall and were informed they would hear strong binaural sounds through headphones during the PPI test. After an acclimation period, two blocks of four-type binaural auditory stimuli were pseudo randomly presented with an inter-stimulus interval of 4-7 s. Each type (P and PP+P with 30, 60, or $120 \mathrm{~ms}$ PP-P time) was presented 20 times. Before each block, five pulse-alone $(\mathrm{P})$ stimuli were presented and discarded to avoid discrepant high intensity responses. The Ps were applied with $115 \mathrm{~dB}$ intensity and the PPs with $85 \mathrm{~dB}$; both consisting of white noise with virtually instantaneous rise and decay duration of 40 and $20 \mathrm{~ms}$, respectively [68-70]. Each test was performed under background (white) noise of $70 \mathrm{~dB}$ of intensity, which was also present during the 3-min interval between the first and second blocks. The stimuli intensity was properly calibrated at the beginning of each test day using a decibel meter. 


\subsection{Data Processing}

\subsubsection{Preprocessing}

EEG, EMG, and EOG (electrooculogram) were recorded using a portable device (brand Brain Products, model V-Amp) with 16 dry electrodes. EEG was acquired through a cap (BrainVision Acticap, Brain Products, Gilching, Germany) with 11 scalp electrodes (10-20 system: F7, F3, Fz, F4, F8, C3, Cz, C4, P3, Pz, P4). Two channels were used for EMG measurement, one electrode was reserved for EOG and one more was used as an additional reference. Sampling rate was set at $512 \mathrm{~Hz}$ for the recording of all electrophysiological signals. Electrode impedance was kept below $15 \mathrm{k} \Omega$. To register the muscular (EMG) acoustic startle response (ASR), two dry electrodes were placed under the right eye: one of them located $2 \mathrm{~cm}$ below the pupil (EMG1) and the other $2 \mathrm{~cm}$ below the outer edge (EMG2). EOG was monitored by an electrode placed $2 \mathrm{~cm}$ above the center of the left eye, only to facilitate artifact removal (eye blinks) from the EEG signals. The right ear lobe was used as reference. To prevent laterality effects (bias), one electrode was placed on the left earlobe and used as an additional reference. EEG and EOG signals were re-referenced offline to the average of left and right earlobes and the (bipolar) EMG signal was formed by the subtraction of EMG2 from EMG1.

EMG, EOG, and EEG signals were analyzed using the MATLAB software running the EEGLAB package [71] and the SASICA plug-in [72]. All signals were notch-filtered at 60,120 , and $180 \mathrm{~Hz}$ to remove power grid interference. Also, to avoid signal delay and distortion, filtering was performed in "zero phase" mode (by reversing the signal and filtering it again). High- and low-pass EMG signal filtering were done with fourth-order Butterworth filters at 24 and $200 \mathrm{~Hz}$ cutoff frequencies, respectively, as recommended for PPI studies $[73,74]$. Although we wanted to remove low-frequency noise from EMG, a greater high-pass cutoff could possibly discard PP responses from the analysis, biasing the data to $\mathrm{P}$ alone responses. Therefore, we chose the lower limit of $24 \mathrm{~Hz}$ for high-pass cutoff recommendation instead of the higher limit of $32 \mathrm{~Hz}$ [74]. The absolute EMG signal envelope was obtained through rectification and low-pass filtering $(15.9 \mathrm{~Hz})$. Signals were then divided into periods of $600 \mathrm{~ms}$, from -300 to $+300 \mathrm{~ms}$ in relation to P stimulus (which occurs at $0 \mathrm{~ms}$ ). The baseline was calculated by averaging the EMG envelope in the time interval of -50 to $0 \mathrm{~ms}$. In each trial, ASR was measured as the maximum amplitude of the EMG envelope in the 20-120 ms interval.

EEG signal drifting was eliminated using a fourth-order Butterworth high-pass filter with cutoff at $0.25 \mathrm{~Hz}$. In order to obtain the ERPs of each subject, the EEG was segmented from -1000 to $1000 \mathrm{~ms}$ in relation to P stimulus. Following, the signal was low-pass $(40 \mathrm{~Hz})$ filtered (fourth order Butterworth) and had its baseline corrected according to the average EEG activity in the -650 to $-150 \mathrm{~ms}$ range. For each channel, trials with amplitudes above $300 \mu \mathrm{V}$ were automatically removed. Myogenic artifacts were automatically removed using Independent Component Analysis (ICA) available in the EEGLAB toolbox [75]. Artifactual components were automatically identified by the SASICA algorithm [72], with its parameters validated on the control group only. Our previous article, which validated our method to obtain neural PPI on the same control group used in this study, describes this procedure in detail [52], comparing it to other methods used in previous studies [76-78].

\subsubsection{EMG and EEG Processing}

The ASR mean for each experimental condition was calculated as the average of ASR peaks of trials belonging to the same condition on the first block. Subjects were classified as "non-responders" and excluded from the study when the mean amplitude of ASR to $P$ was less than $1 \mu \mathrm{V}$. According to this criterion, the number of subjects excluded from the CT, BP, and SZ groups was six, three, and two, respectively. Thus, the final number of participants of this study were respectively 15, 18, and 11 for CT, BP, and SZ groups. Additionally, trial-by-trial exclusion of non-synchronized responses was based solely on the removal of extreme outliers [79] according to the following rules: (i) baseline trial above 
three SDs (standard deviations) from average baseline; (ii) ASR amplitude higher than average +3 SDs; and (iii) trial onset latency three SDs above average.

For each subject, EEG signal averaging over valid trials was performed separately for the four types of auditory stimulation. Next, N100 and P200 (or N1 and P2) were computed as the negative and positive peak in the $60-165 \mathrm{~ms}$ and $165-275 \mathrm{~ms}$ range, respectively. The subtraction of N1 from P2 formed the P2-N1 ERP for each of the four stimulus types. Lastly, the resulting ERPs were spatially averaged according to scalp region, with frontal electrodes F3, F4, F7, F8, and Fz forming Favg, central electrodes C3, C4, and Cz averaged to get Cavg and the parietal electrodes P3, P4, and Pz to get Pavg.

Finally, percentage of PPI was computed for both P2-N1 ERP (from EEG) and muscular ASR (from EMG) according to the formula: \%PPI $=100 \times[1-(\mathrm{P}-\mathrm{PP})] / \mathrm{P}$, where $\mathrm{P}$ is the pulse alone response and $\mathrm{PP}$ is the $\mathrm{PP}+\mathrm{P}$ response.

\subsection{Statistical Analysis}

All statistical analyses were performed with the R software, version 3.4.4 [80]. Group characteristics comparison $(\mathrm{CT} \times \mathrm{BP} \times \mathrm{SZ})$ were performed using analysis of variance (ANOVA) for age and education years, $\chi^{2}$-test for sex and Kruskal-Wallis tests for clinical scores. Significance level was set as 5\% for all statistical tests. For the patient groups, pairwise comparisons $(\mathrm{BP} \times \mathrm{SZ})$ on variables age of onset and treatment start were performed with Student's $t$-tests. Within-group comparisons using Wilcoxon signed-rank tests were also performed to compare clinical scores (BPRS, HAM-D, and YMRS) at STREAM recruitment and PPI session days. The amplitude (P) and \%PPI data (PPI30, PPI60, and PPI120) distribution did not hold normality for the three groups according to visual inspection on skewness and Shapiro-Wilk tests. Therefore, Kruskal-Wallis test was applied for the muscular ASR and the three neural PPI (ERP) scalp regions (Favg, Cavg, and Pavg). When significant group differences were found, one-tailed planned pairwise comparisons were performed with Mann-Whitney/Wilcoxon Rank-sum tests using Bonferroni adjustment based on the number of group comparisons in each measure, i.e., $\mathrm{CT} \times \mathrm{BP}, \mathrm{CT} \times \mathrm{SZ}$, and $\mathrm{BP}$ $\times$ SZ. For post-hoc tests, results were considered significant if $p<0.05$. Kendall correlation was performed separately for each group (CT, BP, and SZ) to assess the relationship between ASR amplitude (P, PPI30, PPI60, and PPI120) and \%PPI data (\%PPI30, \%PPI60, and \%PPI120), and also to compare the clinical scores (BPRS, HAM-D, and YMRS) at STREAM recruitment and PPI test session days.

\section{Results}

\subsection{Demographic and Clinical Data}

Demographic and clinical characteristics of the sample are presented in Table 1. Educational levels were significantly lower in SZ when compared to $\mathrm{CT}[\mathrm{F}(2,41)=3.39, p=0.02]$. Participants displayed group statistical differences in symptoms severity measures (BPRS $\left[\chi^{2}(2)=24.61, p<0.00001\right]$, YMRS [ $\left.\chi^{2}(2)=22.35, p<0.001\right]$, HAM-D $\left.\left[\chi^{2}(2)=15.67, p<0.001\right]\right)$ at STREAM recruitment day, but not at PPI test day, revealing that patients' symptoms were controlled at the test day. Use of atypical antipsychotic medication was different between BP and SZ. Mood stabilizers were only administered to BP patients.

\subsection{Prepulse Inhibition}

Median P and PPI values are reported on Table 2. The muscular ASR to $P$, evaluated by the EMG, was not statistically different between groups $\left[\chi^{2}(2)=0.6 ; p>0.05\right]$. Similarly, neural ASR to $P$ evaluated by P2-N1 was not different between groups at any scalp locations: Favg $\left[\chi^{2}(2)=2.9 ; p>0.05\right]$, Cavg $\left[\chi^{2}(2)=3.7 ; p>0.05\right]$ nor Pavg $\left[\chi^{2}(2)=5.3 ; p>0.05\right]$. Regarding muscular \%PPI (Figure 1A), CT values were significantly higher than SZ for $\%$ PPI60 $[\mathrm{W}(1)=132 ; p=0.014]$ and $\%$ PPI120 $[\mathrm{W}(1)=137 ; p=0.006]$. 
Table 1. Socio-demographic and clinical characteristics of the sample.

\begin{tabular}{|c|c|c|c|c|c|}
\hline Characteristics & $\begin{array}{l}\text { Control } \\
(n=15)\end{array}$ & $\begin{array}{l}\text { Bipolar } \\
(n=18)\end{array}$ & $\begin{array}{l}\text { Schizophrenia } \\
\quad(n=11)\end{array}$ & $\begin{array}{c}\text { Test } \\
\text { Types }\end{array}$ & $\begin{array}{c}\text { Omnibus Statistic and } \\
\text { Significance } \\
\text { Pairwise Comparisons }\end{array}$ \\
\hline Age at STREAM (years) & $26.8 \pm 7.42$ & $25.55 \pm 6.87$ & $27.36 \pm 8.93$ & a & $\mathrm{F}(2,41)=0.22$, n.s. \\
\hline Education (years) & $12.5 \pm 2.69$ & $10.79 \pm 2.48$ & $10.02 \pm 2.37$ & $\mathrm{a}, \mathrm{t}$ & $\mathrm{F}(2,41)=3.39, p=0.02 ; \theta$ \\
\hline $\operatorname{Sex}(\mathrm{m} / \mathrm{f})$ & $9 / 6$ & $10 / 8$ & $8 / 3$ & $c$ & $\chi^{2}(2,41)=0.87$, n.s. \\
\hline Age of onset (years) & - & $24.47 \pm 6.84$ & $25.65 \pm 8.96$ & $\mathrm{~b}$ & $\mathrm{t}(17.10)=0.38$, n.s. \\
\hline PPI test-treat. start (years) & - & $1.57 \pm 0.8$ & $1.84 \pm 0.92$ & $\mathrm{~b}$ & $\mathrm{t}(19.01)=0.81$, n.s. \\
\hline Edinburgh (score) & $17.26 \pm 3.15$ & $17.94 \pm 2.33$ & $17.54 \pm 2.38$ & d & $\mathrm{k}^{2}(2)=0.50$, n.s. \\
\hline BPRS STREAM (score) & $0.93 \pm 2.84$ & $9 \pm 5.58$ & $12.81 \pm 6.86$ & $\mathrm{k}, \mathrm{w}$ & $\mathrm{k}^{2}(2)=24.61, p<0.00001 ; \theta, \delta$ \\
\hline BPRS at PPI test (score) & $1.93 \pm 2.65$ & $3.77 \pm 7.05$ & $7.45 \pm 8.06$ & $\mathrm{k}$ & $\mathrm{k}^{2}(2)=4.05$, n.s. \\
\hline Hamilton D at STREAM (score) & $1.86 \pm 5.16$ & $5.27 \pm 6.02$ & $9.18 \pm 5.84$ & $\mathrm{k}, \mathrm{w}$ & $\mathrm{k}^{2}(2)=15.67, p<0.001 ; \theta, \delta$ \\
\hline Hamilton D at PPI test (score) & $1.93 \pm 3.03$ & $2.5 \pm 3.09$ & $6.27 \pm 6.73$ & k & $\mathrm{k}^{2}(2)=5.45$, n.s. \\
\hline YMRS at STREAM (score) & $0.53 \pm 1.18$ & $13.5 \pm 10.18$ & $5.18 \pm 4.91$ & $\mathrm{k}, \mathrm{w}$ & $\mathrm{k}^{2}(2)=22.35, p<0.001 ; \theta, \delta$ \\
\hline YMRS at PPI test (score) & $0.53 \pm 0.83$ & $3.05 \pm 5.77$ & $2.9 \pm 3.83$ & $\mathrm{k}$ & $\mathrm{k}^{2}(2)=2.75$, n.s. \\
\hline Atypical antipsychotic (\%) & - & $39 \%$ & $82 \%$ & c & $\chi^{2}(1,29)=5.09, p=0.05 ; \beta$ \\
\hline Typical antipsychotic (\%) & - & $6 \%$ & $18 \%$ & c & $\chi^{2}(1,29)=1.17$, n.s. \\
\hline Humor stabilizer (\%) & - & $61 \%$ & - & c & $\chi^{2}(1,29)=10.83, p<0.01 ; \beta$ \\
\hline Benzodiazepines (\%) & - & $22 \%$ & $45 \%$ & c & $\chi^{2}(1,29)=1.72$, n.s. \\
\hline
\end{tabular}

Sex is displayed as the absolute counts for male (m)/female (f) participants. Drug treatment are displayed as the percentage of use in relation to participants of the same group. The remaining characteristics are displayed as the mean \pm the standard deviation. Age is displayed at STREAM recruitment day. Brief Psychotic Rating Scale (BPRS) Hamilton D and Young Mania Rating Scale (YMRS) are displayed at STREAM recruitment day and at PPI test day. Statistical Test Types are indicated as: a-ANOVA $(\mathrm{CT} \times \mathrm{BP} \times \mathrm{SZ})$; $\mathrm{t}-$ Welsh Two Sample $t$-test $(\mathrm{CT} \times \mathrm{BP})$ or $(\mathrm{BP} \times \mathrm{SZ})$ or $(\mathrm{BP} \times \mathrm{SZ})$; $\mathrm{c}-\mathrm{\chi} 2(\mathrm{CT} \times \mathrm{BP} \times \mathrm{SZ})$ or $\mathrm{\chi} 2(\mathrm{BP} \times \mathrm{SZ})$; $\mathrm{k}-$ Kruskal-Wallis test $(\mathrm{CT} \times \mathrm{BP} \times \mathrm{SZ})$; $\mathrm{w}-$ Wilcoxon rank sum test pairwise group comparisons. Statistically significant post-hoc pairwise comparisons: $\theta-\mathrm{CT} \times \mathrm{BP} ; \delta-\mathrm{CT} \times \mathrm{SZ} ; \beta-\mathrm{BP} \times \mathrm{SZ}$.

Table 2. Medians of Acoustic Startle Response (ASR) and percentage Prepulse Inhibition for Control, Schizophrenia, and Bipolar Disorder participants.

\begin{tabular}{|c|c|c|c|c|c|}
\hline Electrode & Response & Control $(n=15)$ & Bipolar $(n=18)$ & Schizophrenia $(n=11)$ & Omnibus Statistic \\
\hline \multirow[t]{4}{*}{ EMG } & P Amp $(\mu \mathrm{V})$ & 2.23 & 1.87 & 3.04 & $\chi^{2}(2)=0.62$, n.s. \\
\hline & \%PPI30 & 60.05 & 48.49 & 21.61 & $\chi^{2}(2)=1.9$, n.s. \\
\hline & \%PPI60 & 60.52 & 52.25 & 33.81 & $\chi^{2}(2)=6.71, p=0.03$ \\
\hline & \%PPI120 & 48.51 & 39.29 & 24.26 & $\chi^{2}(2)=6.81, p=0.03$ \\
\hline \multirow[t]{4}{*}{ Favg } & P Amp $(\mu \mathrm{V})$ & 21.89 & 16.90 & 13.95 & $\chi^{2}(2)=2.94$, n.s. \\
\hline & \%PPI 30 & 48.89 & 34.14 & 39.36 & $\chi^{2}(2)=2.6$, n.s. \\
\hline & \%PPI 60 & 61.36 & 54.90 & 58.55 & $\chi^{2}(2)=1.95$, n.s. \\
\hline & \%PPI 120 & 48.52 & 41.01 & 44.28 & $\chi^{2}(2)=2.86$, n.s. \\
\hline \multirow[t]{4}{*}{ Cavg } & P Amp $(\mu V)$ & 25.26 & 20.97 & 19.47 & $\chi^{2}(2)=3.68$, n.s. \\
\hline & \%PPI 30 & 45.96 & 30.12 & 35.50 & $\chi^{2}(2)=5.11$, n.s. \\
\hline & \%PPI 60 & 60.29 & 50.72 & 54.72 & $\chi^{2}(2)=7.46, p=0.02$ \\
\hline & \%PPI 120 & 48.14 & 43.58 & 48.06 & $\chi^{2}(2)=2.28$, n.s. \\
\hline \multirow[t]{4}{*}{ Pavg } & P Amp $(\mu \mathrm{V})$ & 19.70 & 14.79 & 13.65 & $\chi^{2}(2)=5.26$, n.s. \\
\hline & \%PPI 30 & 46.52 & 29.62 & 34.65 & $\chi^{2}(2)=9.45, p<0.01$ \\
\hline & \%PPI 60 & 61.00 & 35.55 & 50.15 & $\chi^{2}(2)=10.45, p<0.01$ \\
\hline & \%PPI 120 & 47.09 & 32.62 & 40.59 & $\chi^{2}(2)=3.29$, n.s. \\
\hline
\end{tabular}

In bold, are indicated Schizophrenia and/or Bipolar patients with significantly lower \%PPI than the Control group revealed by pairwise $(\mathrm{CT} \times \mathrm{BP}$ or $\mathrm{CT} \times \mathrm{SZ})$ Mann-Whitney/Wilcoxon Rank-sum tests. 


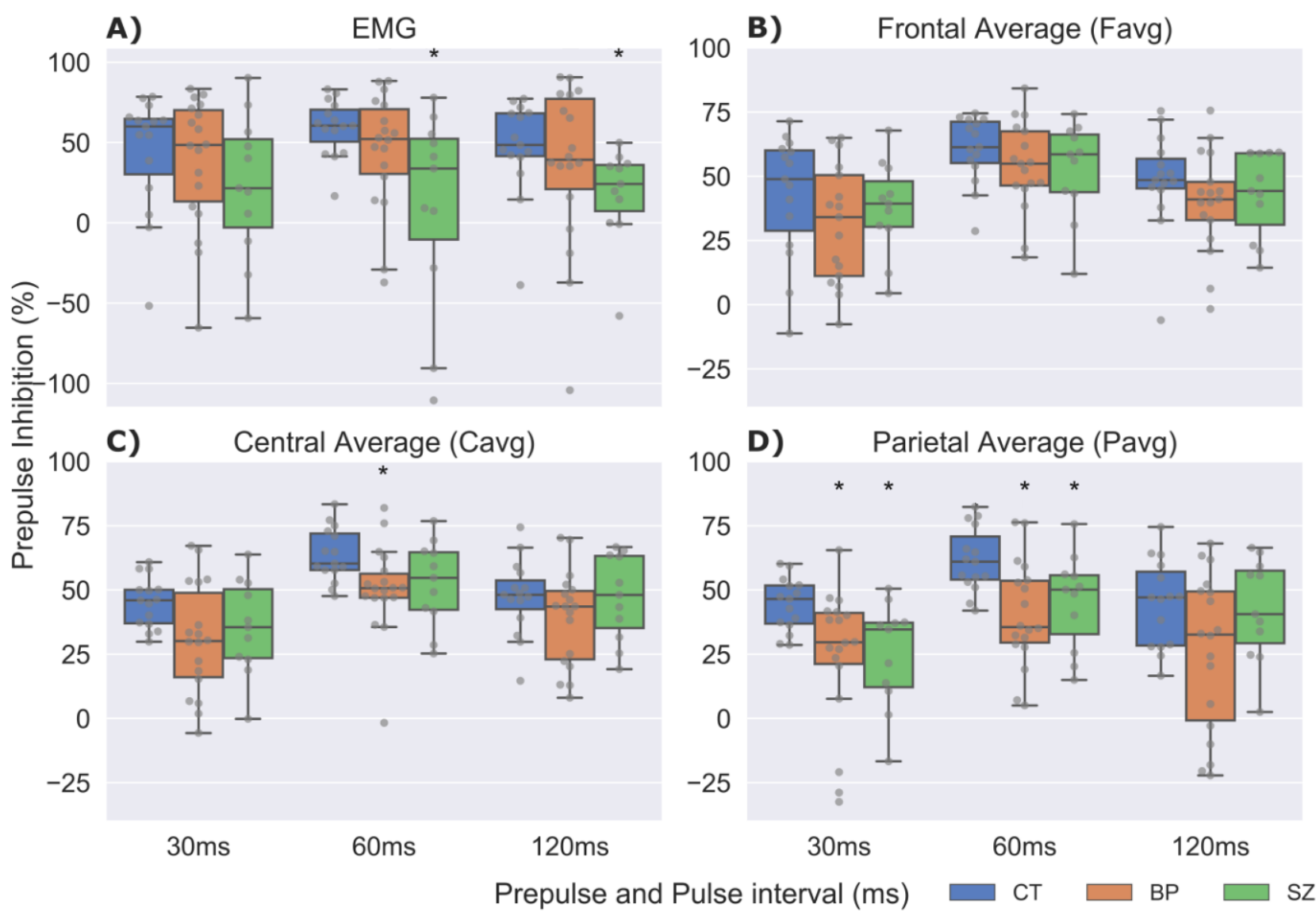

Figure 1. Box- and swarm-plots of muscular and neural P2-N1 PPI for the Prepulse and Pulse intervals of 30, 60, and 120 ms for Control (CT), Manic (BP), and Schizophrenia (SZ) participants. (A) Eye-blink startle inhibition; (B) Average of the frontal electrodes F3, F4, F7, F8, and Fz; (C) Average of the central electrodes C3, Cz, and C4; (D) Average of parietal electrodes P3, Pz, and P4. ${ }^{*} p<0.05$ in the pairwise comparisons for the case groups compared to control groups (CT vs. BP or CT vs. SZ) according to Mann-Whitney/Wilcoxon Rank-Sum Test. Blue boxplots are CT, orange are BP and green represents SZ group. Gray dots are individual \%PPI data for each participant. Note that the percentage scale for EMG has a wider range than the neural \%PPI.

As for neural \%PPI measured by Cavg (Figure 1C), CT displayed significantly higher $\%$ PPI than BP for the \%PPI60 [W(1) = 212; $p=0.007]$. Also, when measured by Pavg (Figure 1D), CT displayed significantly higher \%PPI than BP for \%PPI30 [W(1) = 208; $p=0.011]$ and $\%$ PPI60 $[\mathrm{W}(1)=221 ; p=0.002]$. Accordingly, CT exhibited significantly greater \%PPI than SZ for \%PPI30 [W(1) = 133; $p=0.012]$ and \%PPI60 [W(1)=125; $p=0.041]$.

Kendall correlation analysis on BP group showed a negative association between the HAM-D Score at recruitment day and muscular \%PPI for 30 [Kendall's tau $=-0.47$; $p=0.01$ ], 60 [Kendall's tau $=-0.51 ; p<0.01$ ], and $120 \mathrm{~ms}$ [Kendall's tau $=-0.47 ; p=0.01$ ] P + PP intervals. In contrast, for the same BP group, neural \%PPI60 evaluated by Favg was positively correlated with HAM-D score at recruitment day [Kendall's tau $=0.52 ; p<0.01$ ] Still for BP patients, the YMRS was negatively correlated with neural \%PPI120 measured by Favg [Kendall's tau $=-0.63 ; p<0.01]$.

Figures 2 and 3 show the efficiency of the SASICA algorithm [72] to eliminate the eye-blinks and other artifacts from the RAW signal. Figure 2 shows the topography (grand average ERP) for the pulse alone $(\mathrm{P})$ condition at latencies N1 and P2 with eye-blink artifacts occurring due to startle reflex affect mainly the N1 component (RAW signal). After artifacts removal (SASICA), the N1 component displays normal negative activation across all scalp channels. In Figure 3, it is possible to observe that eye-blinks were completely eliminated from the EOG channel, enabling the identification of the N1 and P1 ERPs even in this 
electrode, due to the underlying brain activity captured by EOG. Figure 4 displays the grand averaged waveforms from $\mathrm{CT}, \mathrm{SZ}$, and $\mathrm{BP}$ groups for the conditions pulse alone $(\mathrm{P})$ and $\mathrm{PP}+\mathrm{P}(30$ and $60 \mathrm{~ms}$ ) at EOG, Favg, Cavg, and Pavg (grey areas signalize statistically significant differences with the control group in neural PPI).
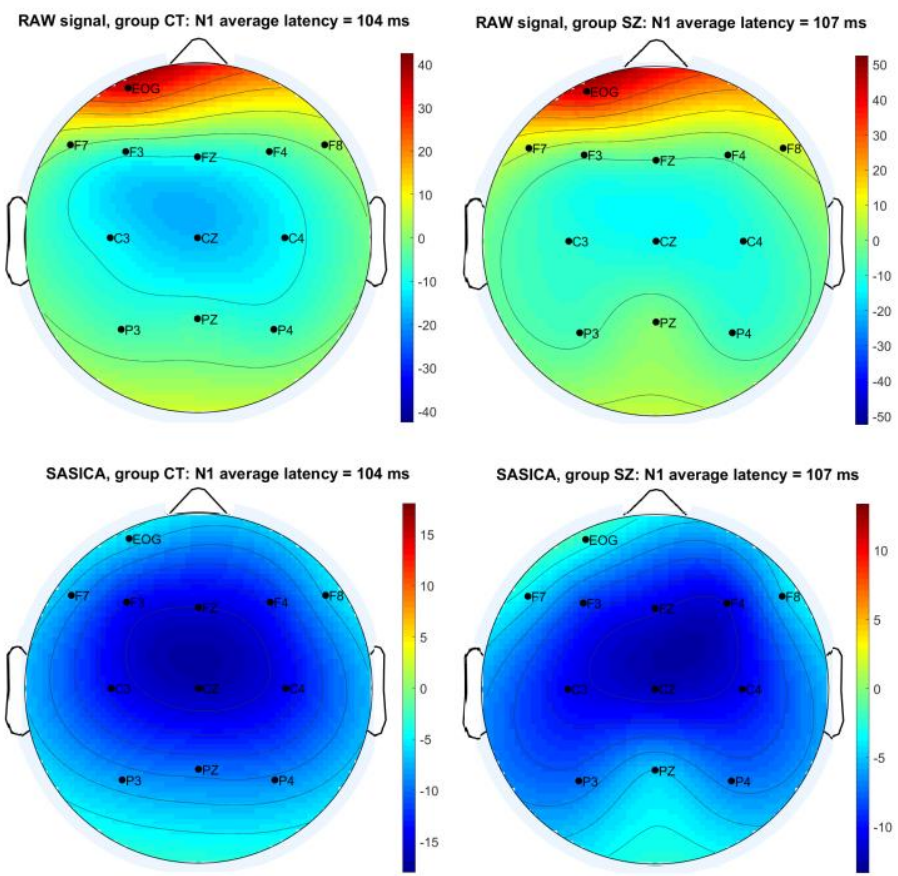

(a)
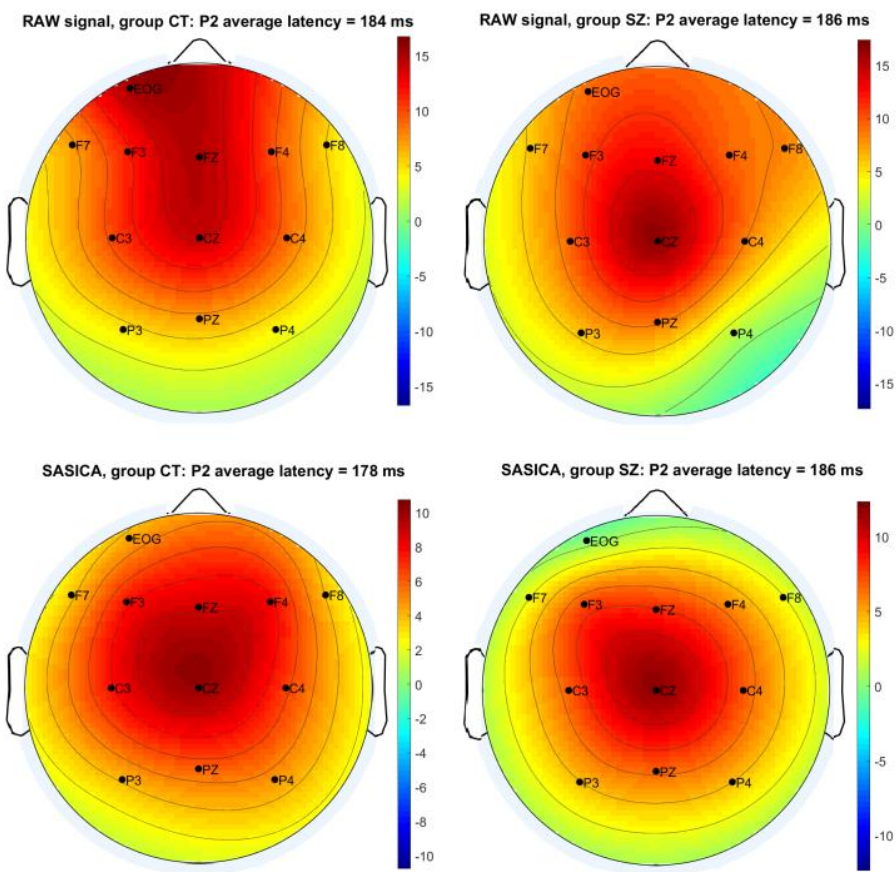

SASICA, group SZ: P2 average latency $=186 \mathrm{~ms}$

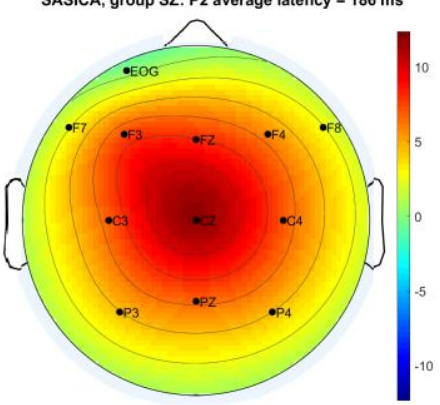

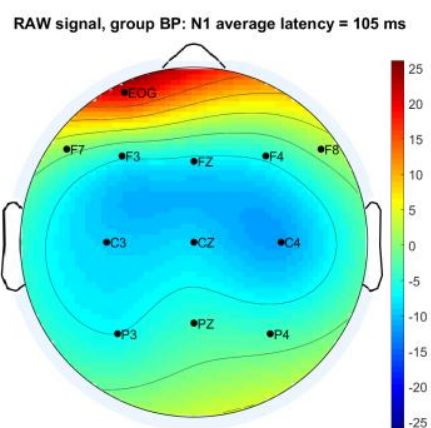
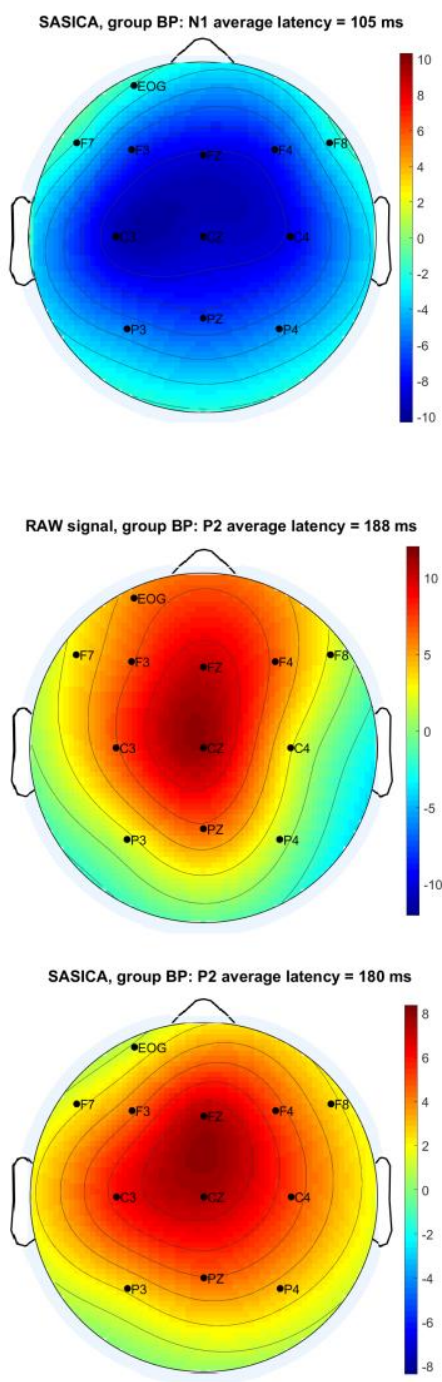

(b)

Figure 2. 2D topography (grand average ERPs) for the pulse alone (P) condition at latencies N1 (a) and P2 (b) from CT, SZ, and BP groups before (RAW signal) and after (SASICA) artifacts removal. 2D topography includes Frontal (F7, F3, Fz, F4, and F8), Central (C3, Cz, and C4) and Parietal (P3, $\mathrm{Pz}$, and P4) channels. Eye-blink artifacts due to startle reflex affect mainly the N1 component (RAW signal). After the artifacts' removal (SASICA), the N1 component displays normal negative activation (blue color) across all scalp channels. 

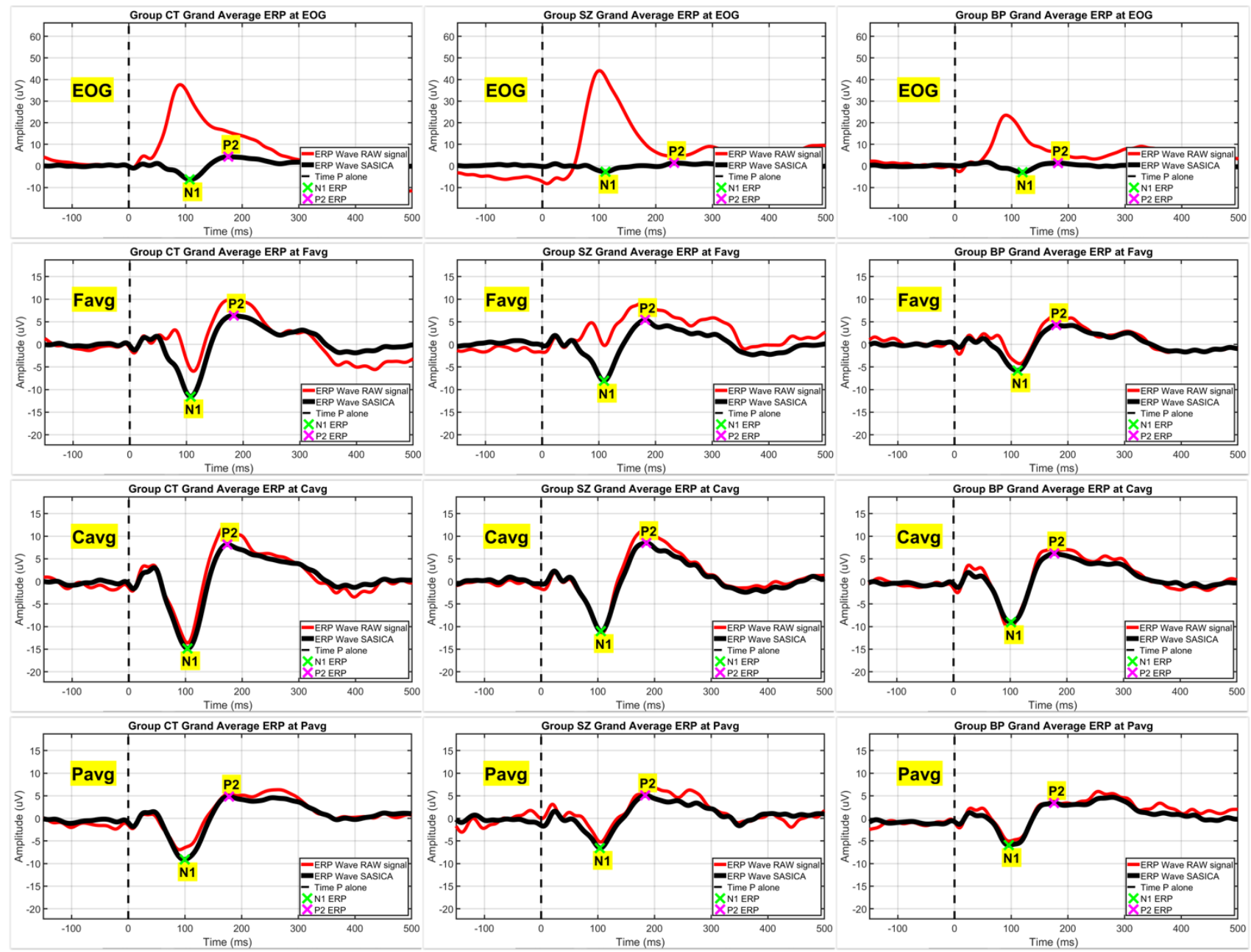

Figure 3. Grand averaged waveforms of all groups before (red line) and after (black line) artifacts' removal on the EOG electrode and on the average of frontal (Favg), central (Cavg) and parietal (Pavg) channels (lines of subfigures). After artifact's removal, the N1 and P2 ERPs (green and magenta crosses, respectively) were identified even on the EOG channel, due to the underlying brain activity captured by this electrode, visible only after complete removal of eye-blinks. 

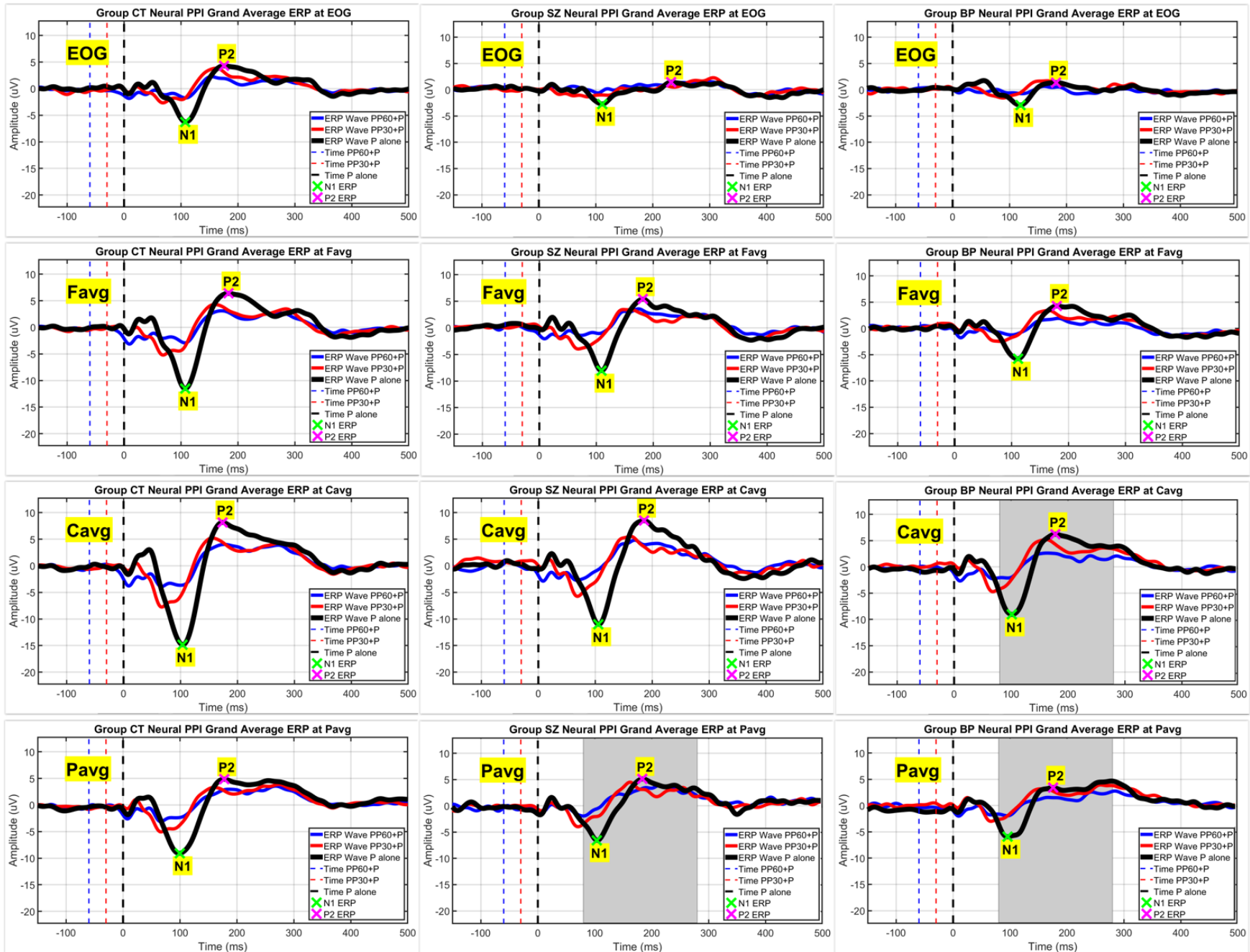

Figure 4. Grand averaged waveforms (after artifacts removal) of from CT, SZ, and BP groups (column subfigures) for the conditions pulse alone (P) and PP + P (30 and $60 \mathrm{~ms})$ at EOG, Favg, Cavg, and Pavg (line subfigures). The N1 and P2 ERPs (green and magenta crosses, respectively) were signalized only for the pulse P condition (black lines), but grand averaged waveforms were also displayed for the PP + P conditions at Prepulse-Pulse intervals of 60 and $30 \mathrm{~ms}$ (blue and red lines, respectively), which were the only conditions were significant differences (highlighted in grey color) with the CT group were found in the neural PPI.

\section{Discussion}

To the best of our knowledge, this is the first time muscular and neural PPI impairments were evaluated in early BP and SZ. We found that only SZ, but not BP patients, presented sensorimotor gating reduction in muscular \%PPI at 60 and $120 \mathrm{~ms} \mathrm{PP}+\mathrm{P}$ intervals. In addition, we observed reduction in neural \%PPI for both BP and SZ patients. These findings suggest that the evaluation of neural PPI may detect gating impairments in a broader manner than the classical muscular PPI paradigm [52].

In classical eye-blink (muscular) PPI, some previous SZ sensorimotor gating investigations found impairments for the $60 \mathrm{~ms}$ but not for the $120 \mathrm{~ms}$ PP + P interval [22,53,81], while others observed just the opposite [82,83]. Some studies found \%PPI reduction in SZ at both 60 and $120 \mathrm{~ms}$ intervals [84,85], but others did not detect any impairment at 60 or $120 \mathrm{~ms}$ intervals [86,87]. The moderate effect size of this phenomenon and methodological aspects that may influence the outcomes probably explain such heterogeneity, as we showed in our recent meta-analysis [32]. We controlled several of these factors by including CT participants that were socio-economically matched to patients. Additionally, the PPI 
test session was performed on average one year and eight months after a patients' first psychotic episode. Drug treatment after the first episode may have reduced the effect size of \%PPI impairments at PPI test session day [69]. The sensorimotor gating impairments using EMG (muscular) were not observed in BP patients. A previous study with BP patients found \%PPI reduction in some subgroups, such as males with high depression levels, but did not show abnormalities in female and euthymic BP groups [33], as well as in manic or mixed groups [57]. In contrast, another investigation described \%PPI reduction at 60 and $120 \mathrm{~ms}$ PP + P intervals [34].

In this study, the neural \%PPI measured by the P2-N1 ERP at the parietal region detected reduction in sensory gating in both BP and SZ groups. Muscular and neural PPI recruit different brain regions, with muscular PPI revealing CSPP circuitry alterations through motor output (detected by the EMG signal) and neural PPI directly reflecting neuronal synchronized firings (detected by the EEG signal). They also occur at different temporal scales. Muscular PPI involves the fast ASR and slower PPI modulation circuitry [24], usually detected at 20-120 ms, not necessarily requiring higher order cortical systems activation. Neural PPI is observed on a distinct temporal scale, with the ERPs N1 and P2 occurring, respectively, 100 and $200 \mathrm{~ms}$ after stimulus onset and necessarily involves cortical regions. In neural PPI, the (auditory) N1 is time-locked to the stimuli onset and indicates that its perception reached the auditory cortex region [88]. The auditory $\mathrm{N} 1$ in response to $\mathrm{P}$ alone stimuli is related mainly to the primary and secondary auditory cortices [88]. Differently, the P2 wave has been reported to be more widely distributed within the brain, with two main sources identified, one in the auditory cortex and the other in the frontoparietal region, as well as other weaker sources in the anterior cingulate cortex and the insula [89]. Furthermore, an auditory inhibition paradigm evaluated by magnetoencephalography recording proposed that the N1m potential source is at the lateral side of the transverse gyrus or superior temporal gyrus [90,91]. The source of N1 and P2 were also estimated in a neural PPI paradigm investigating healthy individuals [92] with low resolution brain electromagnetic tomography [93]. The N1 generating source was estimated in the frontal lobe of the right hemisphere, while the source of P2 was estimated in the right upper parietal lobe. In summary, although methodological differences may play a role in these results, the N1 and P2 source estimation investigations suggest different generating origin for the ERPs according to their inhibition state. Moreover, the inhibited N1 and P2 sources are clearly distinct, indicating that the sensory gating is not constrained to one brain region. Hence, the extension of the classical eye-blink (muscular) PPI with concurrent EEG recordings enabling the evaluation of neural PPI, similarly to the PPI and P50 sequential recording [94,95], adds a significant piece of information to the classical PPI research. Nevertheless, this result should be interpreted with caution, as the detection of \%PPI impairments on the same electrodes does not directly imply that deficits occur in the same brain structures for both patient groups. While EEG is recorded with high temporal resolution and can be considered a neuroimaging tool, and with some advanced techniques being even able to detecting source localization of brain signals [96,97], it still displays a lower spatial resolution than other techniques such as magnetic resonance imaging (MRI) and positrons emission tomography (PET).

We found a negative correlation between muscular \%PPI and the HAM-D score for all PP + P intervals at recruitment day only, not at PPI test session day. Several studies investigating the correlation between symptoms' severity, as measured with scales such as BPRS/PANSS, YMRS and/or Ham-D, and \%PPI levels in a wide range of mental illnesses, as Alzheimer [98], BP [33,99], and SZ [56,83,100-104], did not find significant associations. A small number of studies observed significant correlations between those measures in SZ patients subgroups or for some of the investigated PP + P intervals, such as the PANSS positive or SAPS being negatively correlated to \%PPI60 [53,105] and \%PPI120 [106]. In the present study, we did not find correlations between BPRS, YMRS or HAM-D scores, and \%PPI levels in the SZ patients. It is possible that the neural \%PPI, being a more direct measure, would be more sensitive to correlation measures than muscular \%PPI, but again 
we observed no significant correlation between psychopathological scores and the neural \%PPI in any of the three electrode averages for the SZ patients. To sum up, as sensory gating belongs to automatic processing domains and clinical symptoms are revealed in more complex domains, association between those measures may not be prone to be reliably detected [100,107,108].

The present study has some limitations. First, $22 \%$ of SZ and $45 \%$ of BP patients were treated with benzodiazepines. This class of medications is known to reduce \%PPI levels among healthy individuals in a dose-dependent pattern [109], a limitation that is recurrent among PPI studies, especially in first-episode psychotic patients [100,110,111], with some studies attenuating possible medication effects by restricting the use of such drugs at the PPI test day [54]. We did not restrict inclusion due to the use of any drug, and all schizophrenia and bipolar patients were under antipsychotic, mood stabilizer, or both treatments, and some were prescribed benzodiazepines, but doses were not recorded in this work. Second, in our study, the limited number of subjects in each group thwarted additional analyses that might have provided more information on sensory gating by subgroups, such as sex [112], antipsychotic drug types [113], and severity of psychotic symptoms [114]. Third, similarly to previous neural PPI studies $[76,77,115]$, this study did not evaluate \%PPI on N1 and P2 potentials, separately. The P2-N1 ERP complex is originated in distinct brain regions, therefore biological validity is reduced with this unified analysis. Fourth, we analyzed the signal in the 1-40 Hz range (full band). Sub-band analyses might provide further information [76], as patients' groups may display alterations limited to specific bands. For example, SZ patients have dysfunctions in resting-state high gamma frequencies when compared to healthy people [116], so it is possible that they also present alterations in the PPI when investigated in specific bands. Fifth, frontal lobe plays a major role in inhibition [117,118], but no group differences were detected in this region. The frontal electrodes were the most contaminated by eye-blink artifacts, and the cleaning process may have attenuated the signal in these regions [72]. Sixth, there are several distinct protocols of PPI test, including different intensities, duration, and source of stimuli; herein, we opted to use a set up similar to those used in many studies with schizophrenia and/or bipolar patients [22,32,36,95] and those used in our previous study [52]. Seventh, we did match cases and controls for potential confounding variables (gender, age group, and educational level), but did not control for potential confounding of smoking status. Lastly, the small sample size may have increased the chance of type II errors, which means not enough statistical power to detect the distinct effects for \%PPI in BP and SZ populations. On the other hand, multiple statistical comparisons may have increased the chance of type I errors.

\section{Conclusions}

As implications for future studies, the combination of muscular with neural PPI has the potential to contribute to differential diagnosis after the psychotic outbreak, as different patient groups may display changes in specific electrode regions, band frequencies, or PPI modalities (neural or muscular). Future studies should include larger BP and SZ groups and evaluate other disorders, to assess the predictive validity of combined muscular and neural PPI.

Author Contributions: We declare the following contribution roles: P.R.M., C.S. and C.M.D.-B. conceived the idea. R.S.-M., M.I.Z., F.J.F. and C.S. developed the methodological and analytical strategies. M.I.Z., M.A.V.d.Á., R.S., C.M.D.-B. and C.S. recruited and acquired the data. R.S.-M. and F.J.F. processed the data. R.S.-M., F.J.F. and C.S. analyzed the data. R.S.-M. drafted the manuscript. F.J.F., C.S. and P.R.M. reviewed the manuscript. R.S.-M., M.A.V.d.Á., R.S., C.M.D.-B., P.R.M., F.J.F. and C.S. critically reviewed the manuscript. All authors have read and agreed to the published version of the manuscript. 
Funding: We declare the financial support for the conduct of the research bellow and inform these sources did not play any role in the study design, collection, analysis, interpretation of the data, writing the report and decision to submit the article. P.R.M.-Foundation of Support for Research of the State of São Paulo (FAPESP) grant \#2012/05178-0 and National Council for Scientific and Technological Development (CNPq). C.M.D.-B.-National Council for Scientific and Technological Development (CNPq). R.S.-Foundation of Support for Research of the State of São Paulo (FAPESP) grant \#2013/11167-3. R.S.-M.-Federal University of ABC scholarship.

Institutional Review Board Statement: The study was conducted according to the guidelines of the Declaration of Helsinki, and approved by the Research Ethics Committee of UFABC with protocol 32293214.7.0000.5594/2015.

Informed Consent Statement: Informed consent was obtained from all subjects involved in the study. Subjects were informed that their participation was voluntary, being able to withdraw at any time, without prejudice to their attendance at the institution. Participants signed an Informed Consent Form, which contained information about the justification, objectives, procedures, risks, and benefits of the study to which they were invited to participate. Participants were guaranteed the right to receive information and clarification of any doubts, even though this could affect their willingness to continue participating. It was ensured the security of not being identified, and that all information provided would be kept confidential.

Conflicts of Interest: The authors declare no conflict of interest. The funders had no role in the design of the study; in the collection, analyses, or interpretation of data; in the writing of the manuscript, or in the decision to publish the results.

\section{References}

1. Van Os, J.; Kapur, S. Schizophrenia. Lancet 2009, 374, 635-645. [CrossRef]

2. Yalincetin, B.; Bora, E.; Binbay, T.; Ulas, H.; Akdede, B.B.; Alptekin, K. Formal thought disorder in schizophrenia and bipolar disorder: A systematic review and meta-analysis. Schizophr. Res. 2017, 185, 2-8. [CrossRef]

3. Craddock, N.; Owen, M.J. The beginning of the end for the Kraepelinian dichotomy. Br. J. Psychiatry 2005, 186, 364-366. [CrossRef]

4. $\quad$ Dominguez, M.D.G.; Viechtbauer, W.; Simons, C.J.P.; van Os, J.; Krabbendam, L. Are psychotic psychopathology and neurocognition orthogonal? A systematic review of their associations. Psychol. Bull. 2009, 135, 157-171. [CrossRef] [PubMed]

5. Rosen, C.; Marvin, R.; Reilly, J.L.; DeLeon, O.; Harris, M.S.; Keedy, S.K.; Solari, H.; Weiden, P.; Sweeney, J.A. Phenomenology of First-Episode Psychosis in Schizophrenia, Bipolar Disorder, and Unipolar Depression: A comparative analysis. Clin. Schizophr. Relat. Psychoses 2012, 6, 145A-151A. [CrossRef]

6. Maier, W.; Zobel, A.; Wagner, M. Schizophrenia and bipolar disorder: Differences and overlaps. Curr. Opin. Psychiatry 2006, 19, 165-170. [CrossRef] [PubMed]

7. Kraepelin, E. Dementia Praecox and Paraphrenia; Krieger Publishing Company: Huntington, NY, USA, 1971.

8. Berrettini, W.H. Are schizophrenic and bipolar disorders related? A review of family and molecular studies. Biol. Psychiatry 2000, 48, 531-538. [CrossRef]

9. Tohen, M.; Sanger, T.M.; McElroy, S.L.; Tollefson, G.D.; Chengappa, K.N.; Daniel, D.G.; Petty, F.; Centorrino, F.; Wang, R.; Grundy, S.L.; et al. Olanzapine versus placebo in the treatment of acute mania. Olanzapine HGEH Study Group. Am. J. Psychiatry 1999, 156, 702-709. [CrossRef]

10. Sachs, G.S.; Grossman, F.; Ghaemi, S.N.; Okamoto, A.; Bowden, C.L. Combination of a Mood Stabilizer With Risperidone or Haloperidol for Treatment of Acute Mania: A Double-Blind, Placebo-Controlled Comparison of Efficacy and Safety. Am. J. Psychiatry 2002, 159, 1146-1154. [CrossRef]

11. Lichtenstein, P.; Yip, B.H.; Björk, C.; Pawitan, Y.; Cannon, T.D.; Sullivan, P.F.; Hultman, C.M. Common genetic influences for schizophrenia and bipolar disorder: A population-based study of 2 million nuclear families. Lancet 2009, 373, 1-14. [CrossRef]

12. Craddock, N.; O’Donovan, M.C.; Owen, M.J. The genetics of schizophrenia and bipolar disorder: Dissecting psychosis. J. Med. Genet. 2005, 42, 193-204. [CrossRef] [PubMed]

13. Bora, E.; Yucel, M.; Pantelis, C. Cognitive Impairment in Affective Psychoses: A Meta-analysis. Schizophr. Bull. 2009, 36, 112-125. [CrossRef]

14. Hill, S.K.; Reilly, J.L.; Keefe, R.S.; Gold, J.M.; Bishop, J.R.; Gershon, E.S.; Tamminga, C.A.; Pearlson, G.D.; Keshavan, M.S.; Sweeney, J.A. Neuropsychological Impairments in Schizophrenia and Psychotic Bipolar Disorder: Findings from the Bipolar-Schizophrenia Network on Intermediate Phenotypes (B-SNIP) Study. Am. J. Psychiatry 2013, 170, 1275-1284. [CrossRef] [PubMed]

15. Demjaha, A.; MacCabe, J.H.; Murray, R. How Genes and Environmental Factors Determine the Different Neurodevelopmental Trajectories of Schizophrenia and Bipolar Disorder. Schizophr. Bull. 2011, 38, 209-214. [CrossRef] [PubMed]

16. Trotta, A.; Murray, R.; MacCabe, J.H. Do premorbid and post-onset cognitive functioning differ between schizophrenia and bipolar disorder? A systematic review and meta-analysis. Psychol. Med. 2014, 45, 381-394. [CrossRef] [PubMed] 
17. Johansson, V.; Hultman, C.M.; Kizling, I.; Martinsson, L.; Borg, J.; Hedman, A.; Cannon, T.D. The schizophrenia and bipolar twin study in Sweden (STAR). Schizophr. Res. 2019, 204, 183-192. [CrossRef]

18. Domján, N.; Csifcsák, G.; Drótos, G.; Janka, Z.; Szendi, I. Different patterns of auditory information processing deficits in chronic schizophrenia and bipolar disorder with psychotic features. Schizophr. Res. 2012, 139, 253-259. [CrossRef]

19. Geyer, M.A.; Krebs-Thomson, K.; Braff, D.L.; Swerdlow, N.R. Pharmacological studies of prepulse inhibition models of sensorimotor gating deficits in schizophrenia: A decade in review. Psychopharmacologia 2001, 156, 117-154. [CrossRef]

20. Swerdlow, N.R.; Braff, D.L.; Geyer, M.A. Sensorimotor gating of the startle reflex: What we said 25 years ago, what has happened since then, and what comes next. J. Psychopharmacol. 2016, 30, 1072-1081. [CrossRef]

21. Braff, D.L.; Geyer, M.A.; Swerdlow, N.R. Human studies of prepulse inhibition of startle: Normal subjects, patient groups, and pharmacological studies. Psychopharmacologia 2001, 156, 234-258. [CrossRef]

22. Swerdlow, N.R.; Light, G.A.; Thomas, M.L.; Sprock, J.; Calkins, M.E.; Green, M.F.; Greenwood, T.A.; Gur, R.E.; Gur, R.C.; Lazzeroni, L.; et al. Deficient prepulse inhibition in schizophrenia in a multi-site cohort: Internal replication and extension. Schizophr. Res. 2018, 198, 6-15. [CrossRef]

23. Turetsky, B.I.; Calkins, M.E.; Light, G.A.; Olincy, A.; Radant, A.D.; Swerdlow, N.R. Neurophysiological Endophenotypes of Schizophrenia: The Viability of Selected Candidate Measures. Schizophr. Bull. 2007, 33, 69-94. [CrossRef]

24. Koch, M. The neurobiology of startle. Prog. Neurobiol. 1999, 59, 107-128. [CrossRef]

25. Fendt, M.; Li, L.; Yeomans, J.S. Brain stem circuits mediating prepulse inhibition of the startle reflex. Psychopharmacology 2001, 156, 216-224. [CrossRef]

26. Swerdlow, N.R.; Geyer, M.A.; Braff, D.L. Neural circuit regulation of prepulse inhibition of startle in the rat: Current knowledge and future challenges. Psychopharmacology 2001, 156, 194-215. [CrossRef]

27. Swerdlow, N.R.; Light, G.A. Sensorimotor gating deficits in schizophrenia: Advancing our understanding of the phenotype, its neural circuitry and genetic substrates. Schizophr. Res. 2018, 198, 1-5. [CrossRef] [PubMed]

28. Braff, D.L.; Geyer, M.A.; Light, G.A.; Sprock, J.; Perry, W.; Cadenhead, K.S.; Swerdlow, N.R. Impact of prepulse characteristics on the detection of sensorimotor gating deficits in schizophrenia. Schizophr. Res. 2001, 49, 171-178. [CrossRef]

29. Hammer, T.B.; Oranje, B.; Fagerlund, B.; Bro, H.; Glenthøj, B.Y. Stability of prepulse inhibition and habituation of the startle reflex in schizophrenia: A 6-year follow-up study of initially antipsychotic-naive, first-episode schizophrenia patients. Int. J. Neuropsychopharmacol. 2011, 14, 913-925. [CrossRef] [PubMed]

30. Kumari, V.; Fannon, D.; Geyer, M.A.; Premkumar, P.; Antonova, E.; Simmons, A.; Kuipers, E. Cortical grey matter volume and sensorimotor gating in schizophrenia. Cortex 2008, 44, 1206-1214. [CrossRef]

31. Mackeprang, T.; Kristiansen, K.T.; Glenthoj, B.Y. Effects of antipsychotics on prepulse inhibition of the startle response in drug-naïve schizophrenic patients. Biol. Psychiatry 2002, 52, 863-873. [CrossRef]

32. San-Martin, R.; Castro, L.A.; Menezes, P.R.; Fraga, F.; Simões, P.W.; Salum, C. Meta-Analysis of Sensorimotor Gating Deficits in Patients with Schizophrenia Evaluated by Prepulse Inhibition Test. Schizophr. Bull. 2020, 46, 1482-1497. [CrossRef]

33. Matsuo, J.; Ota, M.; Hidese, S.; Teraishi, T.; Hori, H.; Ishida, I.; Hiraishi, M.; Kunugi, H. Sensorimotor Gating in Depressed and Euthymic Patients with Bipolar Disorder: Analysis on Prepulse Inhibition of Acoustic Startle Response Stratified by Gender and State. Front. Psychiatry 2018, 9, 123. [CrossRef] [PubMed]

34. Sánchez-Morla, E.M.; Mateo, J.; Aparicio, A.; García-Jiménez, M.; Jiménez, E.; Santos, J.L. Prepulse inhibition in euthymic bipolar disorder patients in comparison with control subjects. Acta Psychiatr. Scand. 2016, 134, 350-359. [CrossRef] [PubMed]

35. Perry, W.; Minassian, A.; Feifel, D.; Braff, D.L. Sensorimotor gating deficits in bipolar disorder patients with acute psychotic mania. Biol. Psychiatry 2001, 50, 418-424. [CrossRef]

36. Mao, Z.; Bo, Q.; Li, W.; Wang, Z.; Ma, X.; Wang, C. Prepulse inhibition in patients with bipolar disorder: A systematic review and meta-analysis. BMC Psychiatry 2019, 19, 282. [CrossRef] [PubMed]

37. Swerdlow, N.R.; Light, G.A.; Sprock, J.; Calkins, M.E.; Green, M.F.; Greenwood, T.; Gur, R.E.; Gur, R.C.; Lazzeroni, L.; Nuechterlein, K.H.; et al. Deficient prepulse inhibition in schizophrenia detected by the multi-site COGS. Schizophr. Res. 2014, 152, 503-512. [CrossRef] [PubMed]

38. Quednow, B.B.; Wagner, M.; Westheide, J.; Beckmann, K.; Bliesener, N.; Maier, W.; Kühn, K.-U. Sensorimotor Gating and Habituation of the Startle Response in Schizophrenic Patients Randomly Treated with Amisulpride or Olanzapine. Biol. Psychiatry 2006, 59, 536-545. [CrossRef]

39. Woznica, A.A.; Sacco, K.A.; George, T.P. Prepulse inhibition deficits in schizophrenia are modified by smoking status. Schizophr. Res. 2009, 112, 86-90. [CrossRef]

40. Morales-Muñoz, I.; Jurado-Barba, R.; Fernández-Guinea, S.; Rodríguez-Jiménez, R.; Jiménez-Arriero, M.; Criado, J.R.; Rubio, G Sensory Gating Deficits in First-Episode Psychosis. J. Nerv. Ment. Dis. 2016, 204, 877-884. [CrossRef] [PubMed]

41. Martinez-Gras, I.; Rubio, G.; del Manzano, B.A.; Rodríguez-Jiménez, R.; Garcia-Sanchez, F.; Bagney, A.; Leza, J.C.; Borrell, J. The relationship between prepulse inhibition and general psychopathology in patients with schizophrenia treated with long-acting risperidone. Schizophr. Res. 2009, 115, 215-221. [CrossRef]

42. Earls, H.A.; Curran, T.; Mittal, V. A Meta-analytic Review of Auditory Event-Related Potential Components as Endophenotypes for Schizophrenia: Perspectives From First-Degree Relatives. Schizophr. Bull. 2016, 42, 1504-1516. [CrossRef] [PubMed]

43. Bramon, E.; Rabe-Hesketh, S.; Sham, P.; Murray, R.M.; Frangou, S. Meta-analysis of the P300 and P50 waveforms in schizophrenia. Schizophr. Res. 2004, 70, 315-329. [CrossRef] [PubMed] 
44. De Wilde, O.; Bour, L.; Dingemans, P.; Koelman, J.; Linszen, D. A meta-analysis of P50 studies in patients with schizophrenia and relatives: Differences in methodology between research groups. Schizophr. Res. 2007, 97, 137-151. [CrossRef]

45. Cheng, C.-H.; Chan, P.-Y.S.; Liu, C.-Y.; Hsu, S.-C. Auditory sensory gating in patients with bipolar disorders: A meta-analysis. J. Affect. Disord. 2016, 203, 199-203. [CrossRef] [PubMed]

46. Erickson, M.A.; Ruffle, A.; Gold, J.M. A Meta-Analysis of Mismatch Negativity in Schizophrenia: From Clinical Risk to Disease Specificity and Progression. Biol. Psychiatry 2016, 79, 980-987. [CrossRef] [PubMed]

47. Umbricht, D.; Krljes, S. Mismatch negativity in schizophrenia: A meta-analysis. Schizophr. Res. 2005, 76, 1-23. [CrossRef]

48. Jeon, Y.-W.; Polich, J. Meta-analysis of P300 and schizophrenia: Patients, paradigms, and practical implications. Psychophysiology 2003, 40, 684-701. [CrossRef]

49. Bestelmeyer, P.E.; Phillips, L.H.; Crombie, C.; Benson, P.; St. Clair, D. The P300 as a possible endophenotype for schizophrenia and bipolar disorder: Evidence from twin and patient studies. Psychiatry Res. 2009, 169, 212-219. [CrossRef]

50. Hall, M.-H.; Schulze, K.; Rijsdijk, F.; Kalidindi, S.; McDonald, C.; Bramon, E.; Murray, R.; Sham, P. Are auditory P300 and duration MMN heritable and putative endophenotypes of psychotic bipolar disorder? A Maudsley Bipolar Twin and Family Study. Psychol. Med. 2009, 39, 1277-1287. [CrossRef]

51. O'Donnell, B.; Vohs, J.; Hetrick, W.; Carroll, C.; Shekhar, A. Auditory event-related potential abnormalities in bipolar disorder and schizophrenia. Int. J. Psychophysiol. 2004, 53, 45-55. [CrossRef]

52. San-Martin, R.; Zimiani, M.I.; Noya, C.; Ávila, M.A.V.; Shuhama, R.; Del-Ben, C.M.; Menezes, P.R.; Fraga, F.; Salum, C. A Method for Simultaneous Evaluation of Muscular and Neural Prepulse Inhibition. Front. Neurosci. 2018, 12, 654. [CrossRef] [PubMed]

53. Wang, Z.-R.; Tan, Y.-L.; Yang, F.-D.; Zhang, W.-F.; Zou, Y.-Z.; Tan, S.-P.; Song, C.-S.; Li, Y.-L.; Zhang, W.-H.; Zhou, D.-F. Impaired prepulse inhibition of acoustic startle in Chinese patients with first-episode, medication-naïve schizophrenia. Chin. Med. J. 2013, $126,526-531$.

54. Xue, Y.-Y.; Wang, H.-N.; Xue, F.; Tan, Q.-R. Atypical Antipsychotics Do Not Reverse Prepulse Inhibition Deficits in Acutely Psychotic Schizophrenia. J. Int. Med. Res. 2012, 40, 1467-1475. [CrossRef]

55. Light, G.A.; Swerdlow, N.R.; Rissling, A.J.; Radant, A.; Sugar, C.A.; Sprock, J.; Pela, M.; Geyer, M.A.; Braff, D.L. Characterization of Neurophysiologic and Neurocognitive Biomarkers for Use in Genomic and Clinical Outcome Studies of Schizophrenia. PLoS ONE 2012, 7, e39434. [CrossRef] [PubMed]

56. Meincke, U.; Mörth, D.; Voß, T.; Thelen, B.; Geyer, M.A.; Gouzoulis-Mayfrank, E.; Voss, T. Prepulse inhibition of the acoustically evoked startle reflex in patients with an acute schizophrenic psychosis-A longitudinal study. Eur. Arch. Psychiatry Clin. Neurosci. 2004, 254, 415-421. [CrossRef]

57. Carroll, C.A.; Vohs, J.L.; O’Donnell, B.F.; Shekhar, A.; Hetrick, W.P. Sensorimotor gating in manic and mixed episode bipolar disorder. Bipolar Disord. 2007, 9, 221-229. [CrossRef]

58. Kedzior, K.K.; Koch, M.; Basar-Eroglu, C. Auditory-evoked EEG oscillations associated with prepulse inhibition (PPI) of auditory startle reflex in healthy humans. Brain Res. 2007, 1163, 111-118. [CrossRef] [PubMed]

59. Koch, M.; Schmiedt-Fehr, C.; Mathes, B. Neuropharmacology of altered brain oscillations in schizophrenia. Int. J. Psychophysiol. 2016, 103, 62-68. [CrossRef] [PubMed]

60. Jongsma, H.; Gayer-Anderson, C.; Lasalvia, A.; Quattrone, D.; Mulè, A.; Szoke, A.; Selten, J.-P.; Turner, C.; Arango, C.; Tarricone, I.; et al. Treated Incidence of Psychotic Disorders in the Multinational EU-GEI Study. JAMA Psychiatry 2018, 75, 36-46. [CrossRef]

61. Di Forti, M.; Quattrone, D.; Freeman, T.P.; Tripoli, G.; Gayer-Anderson, C.; Quigley, H.; Rodriguez, V.; Jongsma, H.E.; Ferraro, L.; La Cascia, C.; et al. The contribution of cannabis use to variation in the incidence of psychotic disorder across Europe (EU-GEI): A multicentre case-control study. Lancet Psychiatry 2019, 6, 427-436. [CrossRef]

62. Del-Ben, C.M.; Shuhama, R.; Loureiro, C.M.; Ragazzi, T.C.C.; Zanatta, D.P.; Tenan, S.H.G.; Santos, J.L.F.; Louzada-Junior, P.; Dos Santos, A.C.; Morgan, C.; et al. Urbanicity and risk of first-episode psychosis: Incidence study in Brazil. Br. J. Psychiatry 2019, 215, 726-729. [CrossRef]

63. Overall, J.E.; Gorham, D.R. The brief psychiatric rating scale. Psychol. Rep. 1962, 10, 799-812. [CrossRef]

64. Hamilton, M. A rating scale for depression. J. Neurol. Neurosurg. Psychiatry 1960, 23, 56. [CrossRef] [PubMed]

65. Young, R.C.; Biggs, J.T.; Ziegler, V.E.; Meyer, D.A. A Rating Scale for Mania: Reliability, Validity and Sensitivity. Br. J. Psychiatry 1978, 133, 429-435. [CrossRef] [PubMed]

66. Vilela, J.; Crippa, J.; Del-Ben, C.M.; Loureiro, S. Reliability and validity of a Portuguese version of the Young Mania Rating Scale. Braz. J. Med. Biol. Res. 2005, 38, 1429-1439. [CrossRef]

67. Oldfield, R.C. The assessment and analysis of handedness: The Edinburgh inventory. Neuropsychologia 1971, 9, 97-113. [CrossRef]

68. Braff, D.L.; Light, G.A.; Ellwanger, J.; Sprock, J.; Swerdlow, N.R. Female schizophrenia patients have prepulse inhibition deficits. Biol. Psychiatry 2005, 57, 817-820. [CrossRef] [PubMed]

69. Oranje, B.; Glenthøj, B. Clonidine Normalizes Sensorimotor Gating Deficits in Patients with Schizophrenia on Stable Medication Schizophr. Bull. 2012, 39, 684-691. [CrossRef]

70. Fraga, F.J.; Noya, C.V.; Zimiani, M.I.; Avila, M.A.; Shuhama, R.; Del-Ben, C.M.; Menezes, P.R.; Martin, R.S.; Salum, C. Simultaneous evaluation of prepulse inhibition with EMG and EEG using advanced artifact removal techniques. In Proceedings of the 38th Annual International Conference of the IEEE Engineering in Medicine and Biology Society (EMBC), Orlando, FL, USA, 16-20 August 2016; pp. 5262-5265. [CrossRef] 
71. Delorme, A.; Makeig, S. EEGLAB: An Open Source Toolbox for Analysis of Single-Trial EEG Dynamics Including Independent Component Analysis. J. Neurosci. Methods 2004, 134, 9-21. [CrossRef]

72. Chaumon, M.; Bishop, D.V.; Busch, N.A. A practical guide to the selection of independent components of the electroencephalogram for artifact correction. J. Neurosci. Methods 2015, 250, 47-63. [CrossRef]

73. Blumenthal, T.D.; Cuthbert, B.N.; Filion, D.L.; Hackley, S.; Lipp, O.; van Boxtel, A. Committee report: Guidelines for human startle eyeblink electromyographic studies. Psychophysiology 2005, 42, 1-15. [CrossRef] [PubMed]

74. Boxtel, A.; Boelhouwer, A.; Bos, A. Optimal EMG signal bandwidth and interelectrode distance for the recording of acoustic, electrocutaneous, and photic blink reflexes. Psychophysiology 1998, 35, 690-697. [CrossRef]

75. Delorme, A.; Sejnowski, T.; Makeig, S. Enhanced detection of artifacts in EEG data using higher-order statistics and independent component analysis. NeuroImage 2006, 34, 1443-1449. [CrossRef] [PubMed]

76. Kedzior, K.K.; Martin-Iverson, M.T. Attention-dependent reduction in prepulse inhibition of the startle reflex in cannabis users and schizophrenia patients-A pilot study. Eur. J. Pharmacol. 2007, 560, 176-182. [CrossRef]

77. Abduljawad, K.A.J.; Langley, R.W.; Bradshaw, C.M.; Szabadi, E. Effects of clonidine and diazepan on ppi N1/P2. J. Psychopharmacol. 2001, 14, 258-265.

78. Sommer, K.; Van Der Molen, M.W.; De Pascalis, V. BIS/BAS sensitivity and emotional modulation in a prepulse-inhibition paradigm: A brain potential study. Physiol. Behav. 2016, 154, 100-113. [CrossRef]

79. Ziermans, T.B.; Schothorst, P.F.; Sprong, M.; Magnée, M.J.; van Engeland, H.; Kemner, C. Reduced prepulse inhibition as an early vulnerability marker of the psychosis prodrome in adolescence. Schizophr. Res. 2012, 134, 10-15. [CrossRef] [PubMed]

80. R Core Team. R: A Language and Environment for Statistical Computing; R Foundation for Statistical Computing: Vienna, Austria, 2013.

81. Ludewig, K.; Geyer, M.A.; Etzensberger, M.; Vollenweider, F.X. Stability of the acoustic startle reflex, prepulse inhibition, and habituation in schizophrenia. Schizophr. Res. 2002, 55, 129-137. [CrossRef]

82. Shi, J.; Wang, Z.; Tan, Y.; Fan, H.; An, H.; Zuo, L.; Yang, F.; Tan, S.; Li, J.; Zhang, X.; et al. CHRNA4was associated with prepulse inhibition of schizophrenia in Chinese: A pilot study. Cogn. Neuropsychiatry 2016, 21, 156-167. [CrossRef]

83. Kunugi, H.; Tanaka, M.; Hori, H.; Hashimoto, R.; Saitoh, O.; Hironaka, N. Prepulse inhibition of acoustic startle in Japanese patients with chronic schizophrenia. Neurosci. Res. 2007, 59, 23-28. [CrossRef]

84. Perry, W.; Minassian, A.; Feifel, D. Prepulse inhibition in patients with non-psychotic major depressive disorder. J. Affect. Disord. 2004, 81, 179-184. [CrossRef]

85. Rubio, G.; López-Muñoz, F.; Barba, R.J.; Martínez-Gras, I.; Rodríguez-Jiménez, R.; Espinosa, R.; Nieto, M.P.; Moratti, S.; JiménezArriero, M.; Leza, J.C. Stress induced by the socially evaluated cold-pressor test cause equivalent deficiencies of sensory gating in male subjects with schizophrenia and healthy controls. Psychiatry Res. 2015, 228, 283-288. [CrossRef]

86. Fargotstein, M.; Hasenkamp, W.; Gross, R.; Cuthbert, B.; Green, A.; Swails, L.; Lewison, B.; Boshoven, W.; Keyes, M.; Duncan, E. The effect of antipsychotic medications on acoustic startle latency in schizophrenia. Schizophr. Res. 2018, 198, 28-35. [CrossRef]

87. Bertelsen, B.; Oranje, B.; Melchior, L.; Fagerlund, B.; Werge, T.M.; Mikkelsen, J.D.; Tümer, Z.; Glenthøj, B. Association Study of CHRNA7 Promoter Variants with Sensory and Sensorimotor Gating in Schizophrenia Patients and Healthy Controls: A Danish Case-Control Study. NeuroMolecular Med. 2015, 17, 423-430. [CrossRef]

88. Huotilainen, M.; Winkler, I.; Alho, K.; Escera, C.; Virtanen, J.; Ilmoniemi, R.; Jääskeläinen, I.P.; Pekkonen, E.; Näätänen, R. Combined mapping of human auditory EEG and MEG responses. Electroencephalogr. Clin. Neurophysiol. Potentials Sect. 1998, 108, 370-379. [CrossRef]

89. Joos, K.; Gilles, A.; Van de Heyning, P.; De Ridder, D.; Vanneste, S. From sensation to percept: The neural signature of auditory event-related potentials. Neurosci. Biobehav. Rev. 2014, 42, 148-156. [CrossRef] [PubMed]

90. Inui, K.; Nakagawa, K.; Nishihara, M.; Motomura, E.; Kakigi, R. Inhibition in the Human Auditory Cortex. PLoS ONE 2016, 11, e0155972. [CrossRef] [PubMed]

91. Inui, K.; Tsuruhara, A.; Nakagawa, K.; Nishihara, M.; Kodaira, M.; Motomura, E.; Kakigi, R. Prepulse inhibition of change-related P50m no correlation with P50m gating. SpringerPlus 2013, 2, 588. [CrossRef] [PubMed]

92. De Pascalis, V.; Russo, E. Hypnotizability, Hypnosis and Prepulse Inhibition of the Startle Reflex in Healthy Women: An ERP Analysis. PLoS ONE 2013, 8, e79605. [CrossRef]

93. Pascual-Marqui, R.D.; Michel, C.; Lehmann, D. Low resolution electromagnetic tomography: A new method for localizing electrical activity in the brain. Int. J. Psychophysiol. 1994, 18, 49-65. [CrossRef]

94. Storozheva, Z.I.; Kirenskaya, A.; Novototsky-Vlasov, V.Y.; Telesheva, K.Y.; Pletnikov, M. Startle Modification and P50 Gating in Schizophrenia Patients and Controls: Russian Population. Span. J. Psychol. 2016, 19, E8. [CrossRef]

95. Swerdlow, N.R.; Weber, M.; Qu, Y.; Light, G.A.; Braff, D.L. Realistic Expectations of Prepulse Inhibition in Translational Models for Schizophrenia Research. Psychopharmacology 2008, 199, 331-388. [CrossRef] [PubMed]

96. Cassani, R.; Estarellas, M.; San-Martin, R.; Fraga, F.J.; Falk, T.H. Systematic Review on Resting-State EEG for Alzheimer's Disease Diagnosis and Progression Assessment. Dis. Markers 2018, 2018, 5147815. [CrossRef] [PubMed]

97. Ianof, J.N.; Fraga, F.J.; Ferreira, L.A.; Ramos, R.T.; Demario, J.L.C.; Baratho, R.; Basile, L.F.H.; Nitrini, R.; Anghinah, R. Comparative analysis of the electroencephalogram in patients with Alzheimer's disease, diffuse axonal injury patients and healthy controls using LORETA analysis. Dement. Neuropsychol. 2017, 11, 176-185. [CrossRef] 
98. Hejl, A.-M.; Glenthøj, B.; Mackeprang, T.; Hemmingsen, R.; Waldemar, G. Prepulse inhibition in patients with Alzheimer's disease. Neurobiol. Aging 2004, 25, 1045-1050. [CrossRef]

99. Giakoumaki, S.G.; Roussos, P.; Rogdaki, M.; Karli, C.; Bitsios, P.; Frangou, S. Evidence of Disrupted Prepulse Inhibition in Unaffected Siblings of Bipolar Disorder Patients. Biol. Psychiatry 2007, 62, 1418-1422. [CrossRef]

100. Aggernaes, B.; Glenthoj, B.Y.; Ebdrup, B.H.; Rasmussen, H.; Lublin, H.; Oranje, B. Sensorimotor gating and habituation in antipsychotic-naive, first-episode schizophrenia patients before and after 6 months' treatment with quetiapine. Int. J. Neuropsychopharmacol. 2010, 13, 1383-1395. [CrossRef] [PubMed]

101. Storozheva, Z.I.; Kirenskaya, A.V.; Lazarev, I.E.; Novototskii-Vlasov, V.Y.; Samylkin, D.V.; Fastovtsov, G.A. Prepulse Modification of the Acoustic Startle Reaction in Healthy Subjects and Patients with Schizophrenia. Neurosci. Behav. Physiol. 2012, 42, 128-132. [CrossRef]

102. Takahashi, H.; Iwase, M.; Ishii, R.; Ohi, K.; Fukumoto, M.; Azechi, M.; Ikezawa, K.; Kurimoto, R.; Canuet, L.; Nakahachi, T.; et al. Impaired prepulse inhibition and habituation of acoustic startle response in Japanese patients with schizophrenia. Neurosci. Res. 2008, 62, 187-194. [CrossRef]

103. Swerdlow, N.R.; Light, G.A.; Cadenhead, K.S.; Sprock, J.; Hsieh, M.H.; Braff, D.L. Startle Gating Deficits in a Large Cohort of Patients with Schizophrenia. Arch. Gen. Psychiatry 2006, 63, 1325-1335. [CrossRef]

104. Perry, W.; Feifel, D.; Minassian, A.; Bhattacharjie, I.; Braff, D.L. Information processing deficits in acutely psychotic schizophrenia patients medicated and unmedicated at the time of admission. Am. J. Psychiatry 2002, 159, 1375-1381. [CrossRef]

105. Braff, D.L.; Swerdlow, N.R.; Geyer, M.A. Symptom correlates of prepulse inhibition deficits in male schizophrenic patients. Am. J. Psychiatry 1999, 156, 596-602. [CrossRef] [PubMed]

106. Matsuo, J.; Ota, M.; Hori, H.; Hidese, S.; Teraishi, T.; Ishida, I.; Hiraishi, M.; Kunugi, H. A large single ethnicity study of prepulse inhibition in schizophrenia: Separate analysis by sex focusing on effect of symptoms. J. Psychiatr. Res. 2016, 82, 155-162. [CrossRef] [PubMed]

107. Cadenhead, K.S.; Light, G.A.; Geyer, M.A.; Braff, D.L. Sensory Gating Deficits Assessed by the P50 Event-Related Potential in Subjects with Schizotypal Personality Disorder. Am. J. Psychiatry 2000, 157, 55-59. [CrossRef] [PubMed]

108. Boutros, N.N.; Korzyukov, O.; Jansen, B.; Feingold, A.; Bell, M. Sensory gating deficits during the mid-latency phase of information processing in medicated schizophrenia patients. Psychiatry Res. 2004, 126, 203-215. [CrossRef]

109. Schächinger, H.; Müller, B.U.; Strobel, W.; Langewitz, W.; Ritz, R. Midazolam effects on prepulse inhibition of the acoustic blink reflex. Br. J. Clin. Pharmacol. 1999, 47, 421-426. [CrossRef] [PubMed]

110. Schizophrenia, F.-E.; Ludewig, K.; Geyer, M.A.; Vollenweider, F.X. Deficits in prepulse inhibition and habituation in nevermedicated, first-episode schizophrenia. Biol. Psychiatry 2003, 54, 121-128. [CrossRef]

111. Hammer, T.B.; Oranje, B.; Skimminge, A.; Aggernæs, B.; Ebdrup, B.H.; Glenthøj, B.; Baaré, W. Structural brain correlates of sensorimotor gating in antipsychotic-naive men with first-episode schizophrenia. J. Psychiatry Neurosci. 2013, 38, 34-42. [CrossRef]

112. Kumari, V.; Aasen, I.; Sharma, T. Sex differences in prepulse inhibition deficits in chronic schizophrenia. Schizophr. Res. 2003, 69, 219-235. [CrossRef]

113. Kumari, V.; Soni, W.; Sharma, T. Prepulse inhibition of the startle response in risperidone-treated patients: Comparison with typical antipsychotics. Schizophr. Res. 2002, 55, 139-146. [CrossRef]

114. Greenwood, T.A.; Light, G.A.; Swerdlow, N.R.; Calkins, M.E.; Green, M.F.; Gur, R.E.; Gur, R.C.; Lazzeroni, L.C.; Nuechterlein, K.H.; Olincy, A.; et al. Gating Deficit Heritability and Correlation with Increased Clinical Severity in Schizophrenia Patients with Positive Family History. Am. J. Psychiatry 2016, 173, 385-391. [CrossRef] [PubMed]

115. De Pascalis, V.; Cozzuto, G.; Russo, E. Effects of personality trait emotionality on acoustic startle response and prepulse inhibition including N100 and P200 event-related potential. Clin. Neurophysiol. 2013, 124, 292-305. [CrossRef]

116. Moran, L.V.; Hong, L.E. High vs Low Frequency Neural Oscillations in Schizophrenia. Schizophr. Bull. 2011, 37, 659-663. [CrossRef] [PubMed]

117. Oranje, B.; Geyer, M.A.; Bocker, K.B.; Kenemans, J.L.; Verbaten, M.N. Prepulse inhibition and P50 suppression: Commonalities and dissociations. Psychiatry Res. 2006, 143, 147-158. [CrossRef] [PubMed]

118. Erin, A.H.; Hazlett, E.A.; Buchsbaum, M.S. Sensorimotor gating deficits and hypofrontality in schizophrenia. Front. Biosci. 2001, 6, d1069-d1072. [CrossRef] 